УДК 327

DOI 10.18413/2687-0967-2020-47-1-202-210

\title{
УКРАИНСКО-АЗЕРБАЙДЖАНСКИЕ ОТНОШЕНИЯ: ОСНОВНЫЕ СФЕРЫ СОТРУДНИЧЕСТВА, ПРОБЛЕМЫ И ПЕРСПЕКТИВЫ РАЗВИТИЯ
}

\section{UKRAINE-AZERBAIJAN RELATIONS: BASIC FIELDS OF COOPERATION, PROBLEMS AND PROSPECTS FOR DEVELOPMENT}

\author{
Д.А. Белащенко, И.Ф. Шоджонов \\ D.A. Belashchenko, I.F. Shodzhonov
Национальный исследовательский Нижегородский государственный университет им. Н.И. Лобачевского, Россия, 603950, г. Нижний Новгород, пр. Гагарина, 23 \\ National Research Lobachevsky State University of Nizhni Novgorod, \\ 23 Gagarin Avenue, Nizhny Novgorod, 603950, Russia \\ E-mail: dmi-belashhenko@yandex.ru, shodzhonov@inbox.ru
}

\begin{abstract}
Аннотация
Проблема межгосударственных отношений является одной из самых обсуждаемых в современном академическом сообществе. За период, последовавший за распадом СССР, регион постсоветского пространства и новые независимые государства заняли важную нишу в современной системе международных отношений. Украина и Азербайджан превратились во влиятельных акторов, чья политика оказывает значительное влияние на развитие региональных процессов на постсоветском пространстве. Стремительное развитие данного региона и рост его геополитического значения вкупе с важностью «украинского» и «азербайджанского» факторов играют решающую роль в обосновании актуальности заявленной темы. Объектом данного исследования выступает эволюция украинскоазербайджанских отношений в период с 1991 по 2019 годы. В рамках статьи авторы рассматривают особенности становления и развития двусторонних отношений, формирования ключевых сфер сотрудничества, существующие проблемы и противоречия, а также перспективы дальнейшего взаимодействия между Украиной и Азербайджаном. Особое внимание уделяется сотрудничеству в рамках международных организаций и программ (ОДЭР-ГУАМ, «Восточное партнерство») и анализу региональных кризисных процессов (Нагорно-Карабахский конфликт, украинский кризис, сецессия Крыма, конфликт в Донбассе), оказывающих прямое влияние на формирование внешнеполитической линии государств по отношению друг к другу.
\end{abstract}

\begin{abstract}
The problem of interstate relations is one of the most discussed in the modern academic community. In the period following the collapse of the USSR, the region of the post-Soviet space and the new independent states occupied an important niche in the modern system of international relations. Ukraine and Azerbaijan have become influential actors whose policies have a significant impact on the development of regional processes in the postSoviet space. The rapid development of this region and the growth of its geopolitical significance, coupled with the importance of the «Ukrainian» and «Azerbaijani» factors, play a decisive role in substantiating the relevance of the stated topic. The object of this study is the evolution of Ukrainian-Azerbaijani relations from 1991 to 2019. In the framework of the article, the authors consider the features of the formation and development of bilateral relations, the formation of key areas of cooperation, existing problems and contradictions, as well as prospects for further interaction between Ukraine and Azerbaijan. Particular attention is paid to cooperation in the framework of international organizations and programs (ODED-GUAM, «Eastern Partnership») and analysis of regional crisis processes (Nagorno-Karabakh conflict, Ukrainian crisis, Crimea secession, conflict in the Donbass), which have a direct impact on the formation of the foreign policy of the states in relation to each other.
\end{abstract}

Ключевые слова: Азербайджан, Украина, постсоветское пространство, политическая элита, двусторонние отношения, дипломатия, ОДЭР-ГУАМ, Восточное партнерство, украинский кризис, Нагорно-Карабахский конфликт. 
Key words: Azerbaijan, Ukraine, post-Soviet space, political elite, bilateral relations, diplomacy, ODEDGUAM, Eastern Partnership, Ukrainian crisis, Nagorno-Karabakh conflict.

Межгосударственные отношения и интеграционные процессы на постсоветском пространстве являются весьма популярными и востребованными темами в академическом сообществе России [Татаринцев, 2011; Внешняя политика стран СНГ..., 2017] и зарубежных стран [Croissant, Aras, 1999; Kembayev, 2009]. В то же время большое количество работ посвящено изучению и анализу взаимодействия России с бывшими республиками СССР [Андронова, 2010; Татаринцев, 2011], а также деятельности наиболее влиятельных региональных международных организаций (СНГ, ОДКБ, ЕАЭС) [Пивовар, 2008; Быков, 2009]. При этом часто вне поля зрения исследователей остаются внешняя политика других важных акторов постсоветского пространства, а также деятельность альтернативных организаций и проектов (ОДЭР-ГУАМ, «Восточное партнерство»). По этой причине стоит обратить внимание на государства, являющиеся, по своей сути, одними из ведущих в регионе, а именно на Украину и Азербайджан. Помимо того, что и Киев, и Баку с момента обретения независимости претендовали на проведение самостоятельной внешней политики, с середины 2000-х гг. они активно сотрудничали в рамках альтернативных организаций и проектов, фактически позиционируя себя в качестве новых центров постсоветского пространства.

Современная история отношений двух государств берет свое начало в конце 1991 г., когда было подписано Беловежское соглашение, зафиксировавшее распад СССР. Официальные дипломатические отношения между Украиной и Азербайджаном были установлены в 1992 г. В силу разных причин окончательное оформление отношений в виде открытия посольств затянулось на несколько лет, вплоть до 1996-1997 гг.

Период первых президентов Азербайджана А.Н. Муталибова и А.Г. Эльчибея, а также Л.М. Кравчука на Украине совпал с решением критических внутренних проблем и установлением дипломатических отношений с ведущими государствами мира. Соответственно, в первой половине 1990-х гг. Киев и Баку в силу объективных причин не рассматривали другу друга в качестве важных партнеров.

Кардинальные изменения начали происходить после прихода к власти в Азербайджане в октябре 1993 г. Г.А. Алиева и Л.Д. Кучмы на Украине в июле 1994 г. Предвыборная программа последнего строилась на сближении с Россией, государствами постсоветского пространства и интенсификации отношений в рамках международных организаций, в частности СНГ. В целом, именно период 1995-2005 гг. стал отправной точкой, когда была заложена нормативно-правовая база взаимодействия Украины и Азербайджана.

В дальнейшем с приходом новых лидеров В.А. Ющенко и И.Г. Алиева углубились межгосударственные контакты в области экономической кооперации, уделялось особое внимание вопросам ассимиляции и социализации украинцев и азербайджанцев в условиях принимающего сообщества. Данный аспект был наиболее важен для Азербайджана ввиду того, что на Украине существует достаточно крупная азербайджанская диаспора, которая активно участвует во внутриполитической жизни страны [Роль, место и вес азербайджанской диаспоры в Украине..., 2019].

Однако в этот же период наметились и определенные противоречия между двумя государствами. Причиной этого стала новая внешнеполитическая риторика украинского руководства, которая после «Оранжевой революции» 2004 г. стала подчеркнуто «гипердемократической», что было воспринято в Баку весьма настороженно. Однако именно в этот период интенсифицировалась политика Украины на закавказском направлении, и была предпринята попытка активизации деятельности в рамках ГУАМ (до 2005 года - ГУУАМ) [Белащенко, 2012, с. 340].

Период нахождения В.Ф. Януковича в статусе президента не ознаменовался значительным развитием двусторонних отношений. Основополагающими вопросами на повестке дня оставались энергетическая сфера, экономическое сотрудничество и процесс урегулирования Нагорно-Карабахского конфликта. Несмотря на то, что В.Ф. Янукович декларировал пересмотр внешнеполитического курса своего предшественника в пользу улучшения отношений с Россией и странами постсоветского пространства, на практике реали- 
зовывалась политика «многовекторности» или «маятника», где больший приоритет отдавался европейскому направлению [Бабенко, 2016, с. 125].

Подобная внешнеполитическая неопределенность стала одной из причин массовых протестов на Украине, начавшихся в ноябре 2013 г. и закончившихся бегством В.Ф. Януковича и рядом кардинальных потрясений для государства. В условиях разразившегося кризиса, сецессии Крыма, массовых протестов в юго-восточных регионах, начала боевых действий в Донбассе новое украинское руководство пыталось выстраивать диалог с Азербайджаном, в том числе и с позиции страны, «пострадавшей» от конфликта [Гулиев, 2014; 2015; 2017]. То есть риторика президента П.А. Порошенко формировалась на основе сравнения Нагорно-Карабахского конфликта и событий в Крыму и Донбассе [Порошенко позвал Алиева на войну, 2018], несмотря на всю спорность подобных суждений [Маркедонов, 2018].

На сегодняшний день можно выделить несколько «опорных точек» украинскоазербайджанских отношений [Губа, 2012]:

1. Военно-техническое сотрудничество.

2. Поставки и транзит энергоресурсов.

3. Конфликты в Нагорном Карабахе и Донбассе, а также позиция по Крыму.

4. Отношения в рамках ГУАМ и «Восточного партнерства».

Рассмотрим каждое из этих направлений двусторонних отношений более подробно.

Военно-техническое сотрудничество (BTC). Последствия Нагорно-Карабахского конфликта, активная фаза которого завершилась в 1994 г. фактическим поражением Азербайджана, привела к пересмотру официальным Баку как направлений внешнеполитической деятельности, так и списка потенциальных союзников и поставщиков вооружений. В свою очередь, Украина, получившая после распада СССР большое количество и военной техники, и вооружений, и технологий, и производственных мощностей, была заинтересована в укреплении своих позиций на рынке оружия и поиске новых покупателей. Азербайджан выступал в качестве привлекательного варианта, поскольку не только обладал значительными финансовыми ресурсами и реальными потребностями в военных закупках, но и являлся партнером Украины по организации ГУАМ [Ниязов, 2014, с. 37], основанной в 1997 г.

Началом систематического военно-технического сотрудничества между Украиной и Азербайджаном принято считать конец 1990-х гг. В тот период также происходила интенсификация отношений в рамках ГУАМ и переговоров относительно поставок азербайджанских энергоресурсов в Украину. Однако активизация военно-технического сотрудничества произошла в период президентства В.А. Ющенко. К 2007 г. Украина наряду с Россией, Турцией, Беларусью и Румынией вошла в число основных партнеров Азербайджана в данной сфере [Ниязов, 2014, с. 39]. В последующие годы объемы поставок и номенклатура вооружений только увеличивались. Стороны также вели сотрудничество в рамках передачи технологий, декларировали общие разработки, проводили совместные военные учения, разрабатывали проекты создания миротворческого батальона в рамках ГУАМ [Полухов, 2008, с. 143]. Существенным стимулом к развитию ВТС стала «пятидневная война» 2008 г. между Россией и Грузией.

В то же время активное военно-техническое сотрудничество Украины и Азербайджана, особенно перманентный рост объемов и номенклатуры поставляемых вооружений вызывали негативную реакцию со стороны Армении, опасавшейся усиления военного потенциала Баку. Именно поэтому Ереван активно закупал вооружение у своих партнеров по Организации Договора о коллективной безопасности, прежде всего, у России. Таким образом, возникала угроза нарушения региональной стабильности в Закавказье [Aliev, 2007; The International Politics of the Armenian-Azerbaijani Conflict..., 2018].

После 2014 г., в силу сложившейся ситуации, основным потребителем продукции ВПК становятся собственные вооруженные силы. Тем не менее ВТС Украины и Азербайджана продолжает оставаться одной из основных сфер двусторонних отношений. Однако наблюдаются негативные процессы, поскольку перечень поставляемых Украиной вооружений существенно сократился, информация о разработке совместных проектов отсутствует в открытых источниках.

Поставки и транзит энергоресурсов. Данный аспект взаимоотношений является одним из драйверов украинско-азербайджанских отношений. Ввиду отсутствия у Украины 
больших объемов собственных энергоресурсов, Киев уделял особое внимание поиску потенциальных экспортеров нефти и, прежде всего, газа. Важным пунктом в повестке дня администраций В.А. Ющенко, П.А. Порошенко и действующего президента В.А. Зеленского было сокращение энергетической зависимости от России. В качестве альтернативных поставщиков энергоресурсов в течение длительного периода рассматривался Азербайджан, являющийся одним из мировых лидеров по запасам углеводородов [Oil and Geopolitics in the Caspian Sea Region, 1999; Özdal, Demydova, 2011].

В то же время для Азербайджана Украина являлась лишь одним из вариантов по транспортировке углеводородов в страны Европы. Долгое время в качестве приоритетного направления для Баку выступал маршрут через территорию Грузии и Турции (в частности, запущенный в 2003 году нефтепровод Баку - Тбилиси - Джейхан). Единственным серьезным достижением в энергетической сфере можно считать совместную эксплуатацию нефтепровода «Одесса - Броды», построенного в 2001 году. Как отмечает Н.А Алексеева [2018], первоначально Россия «предлагала использовать нефтепровод для реверсных поставок российской нефти в страны Средиземноморья, этот план был реализован. В 2010 г. реверсные поставки были остановлены, по трубопроводу началась прокачка азербайджанской нефти в Беларусь. Также планировалось начать поставки сырья из Азербайджана в Чехию, но этот план не увенчался успехом. В результате эксплуатация трубопровода была прекращена. По итогам переговоров с Петром Порошенко, в 2016 г. президент Азербайджана Ильхам Алиев сообщил о планах по реанимации проекта».

Что касается ситуации с поставками и транзитом азербайджанского газа, то данная тема продолжает оставаться своеобразным «камнем преткновения» для отношений двух стран. Украина неоднократно выступала с проектами по использованию своей территории, инфраструктуры и танкеров для прокачки и транспортировки азербайджанского газа, но эти проекты были отклонены Баку, либо перенесены на неопределенный срок. Для Азербайджана гораздо больший практический интерес представляют совместные проекты с Турцией (Трансанатолийский газопровод), Грузией и Румынией (AGRI - Azerbaijan, Georgia, Romania Interconnection) и сотрудничество с Россией в Каспийском регионе.

Конфликты в Нагорном Карабахе и Донбассе. Нагорно-Карабахский конфликт между Азербайджаном и Арменией, начавшийся еще в 1980-е гг., на современном этапе находится в стадии латентного, когда ни одна из сторон не хочет идти на уступки [Тhе International Politics of the Armenian-Azerbaijani Conflict, 2017, p. 150]. Периодические обострения, многочисленные раунды переговоров, идеологическое значение утраты Нагорного Карабаха и ряда других территорий для азербайджанской политики продолжают поддерживать данный конфликт в качестве одной из наиболее значимых проблем для постсоветского пространства и Закавказья.

Выбор Киева, сделанный в пользу позиции Азербайджана, представляется закономерным, поскольку, в отличие от Баку, Ереван не мог предложить Украине ни масштабное экономическое сотрудничество, ни поставки энергоресурсов. Среди других причин, определивших позицию Киева по Нагорно-Карабахскому конфликту, можно выделить географическое положение Украины, расположенной на стыке нескольких регионов; скептическое отношение украинских властей к возможностям федерализации страны и нежелание предоставления культурной автономии национальным меньшинствам; роль азербайджанской диаспоры [Курылев, 2019].

Изначально позиция Украины по Нагорно-Карабахскому конфликту базировалась на двух аспектах: Киев не признает геноцид армян в Османской империи в период Первой мировой войны и поддерживает азербайджанский вариант урегулирования [Valiyev, 2014, p. 3]. Данная политическая позиция не представляется оптимальной с точки зрения выстраивания Украиной взаимовыгодных отношений с государствами Закавказья. В то же время возможность получения азербайджанских энергоресурсов, а также в перспективе выход на энергетические рынки других прикаспийских государств (Ирана, Казахстана, Туркменистана) представлялись для Киева более выгодным вариантом [В ожидании бури: Южный Кавказ, 2018, с. 169].

Л.М. Кравчук и Л.Д. Кучма настаивали на необходимости возврата территорий в состав Азербайджана. В.А Ющенко, в свою очередь, заявлял о возможности отправки в зону конфлик- 
та миротворческого контингента ГУАМ [Valiyev, 2017, p. 135]. В.Ф. Янукович также проводил политику по поддержке Азербайджана в карабахском вопросе. Аналогичной позиции придерживался и П.А. Порошенко. Действующий президент В.А. Зеленский пока не отметился публичными заявлениями относительно Нагорно-Карабахского конфликта, но нет оснований предполагать, что новая администрация откажется от преемственности в данном вопросе.

В случае с украинским кризисом Азербайджан вынужден был использовать гибкую модель политики. С одной стороны, Баку должен был поддержать своего партнера, результатом чего стало осуждение «Крымской весны» и действий ДНР и ЛНР на уровне официальных властей [Valiyev, 2014] и азербайджанской диаспоры Украины. С другой, Азербайджан не был настроен на постоянную жесткую риторику в адрес России, будучи заинтересованным в дальнейшем развитии отношений с Москвой. Кризис дал Азербайджану выход на энергетический рынок Европы, но в то же время осложнил политический аспект межгосударственного взаимодействия на пространстве СНГ. Если до 2014 г. Азербайджан старался вести дружественную политику со всеми государствами СНГ, за исключением Армении, то после воссоединения Крыма с Россией и началом конфликта в Донбассе вынужден придерживаться политики нейтралитета [В ожидании бури: Южный Кавказ, 2018, с. 171].

Еще одним важным аспектом для Азербайджана стала возможность вновь привлечь международное внимание к ситуации с Нагорным Карабахом. Критикуя действия России в ситуации с Крымом, Баку проводит параллели с ситуацией вокруг своего бывшего региона: в схожих, по мнению Азербайджана, случаях, мировое сообщество применяет двойные стандарты, оказывая санкционное давление на Россию и не используя никаких мер в отношении Армении [Valiyev, 2017. p. 137].

Отношения в рамках ГУАМ и Восточного партнерства. Организация за демократию и экономическое развитие - ГУАМ (ОДЭР-ГУАМ) и проект «Восточное партнерство» часто рассматриваются в качестве альтернатив для международных организаций постсоветского пространства. Несмотря на ресурсную ограниченность первой и нереализованный потенциал второго, они действительно стали значимыми региональными явлениями, закрепившими неоднородность и фрагментацию постсоветского пространства. В рамках ГУАМ и «Восточного партнерства» Украина позиционировала себя в качестве полноценного лидера, в то время как позиция Азербайджана была более сдержанной и прагматичной.

Несмотря на заявленные экономические, транспортно-логистические, энергетические и инфраструктурные цели ГУАМ-ГУУАМ-ОДЭР-ГУАМ, на практике большое внимание отводилось политической составляющей. Вместо создания полноценной самодостаточной организации получилась попытка перехватить инициативу у находящегося в кризисе СНГ и ограничить влияние России на постсоветском пространстве. Кроме того, большое значение имела роль внешнего фактора, прежде всего, позиции США. Тем не менее в первые годы существования организации, а также в период 2005-2008 гг. Азербайджан и Украина рассматривали возможность реализации совместных проектов в сфере экономики, энергетики и логистики именно на площадке данной организации. Определенный интерес к ГУАМ проявляли ведущие международные организации (ЕС, ОБСЕ и др.) [Полухов, 2008, с. 135-140]. Однако отсутствие консолидированной позиции государств-участников, превалирование политической составляющей над другими сферами, постепенное снижение интереса как самих членов, так и мирового сообщества привели в итоге к практически полной остановке деятельности ГУАМ.

В случае с «Восточным партнерством» позиция Азербайджана изначально отличалась от позиции Украины. Если в Киеве проект рассматривался в качестве одного из промежуточных этапов в процессе европейской интеграции, то Азербайджан делал ставку на экономическое сотрудничество с ЕС, не предпринимая усилий по политическому сближению с Брюсселем. При подведении промежуточных итогов реализации инициатив «Восточного партнерства» Азербайджан оказался на предпоследнем месте среди шести участников [Гомулка, 2015, c. 52-53]. Несмотря на финансовую поддержку со стороны ЕС и реализации ряда проектов на территории Азербайджана, в Баку не рассматривали возможность осуществления широкого спектра политических реформ, отдавая предпочтение изменениям в экономической сфере. 
Украина и Азербайджан являются ключевыми странами постсоветского пространства с собственным видением своей роли в региональных политических и экономических процессах. Позиции Киева и Баку подкреплялись разными факторами. В первом случае акцент делался на экономический потенциал, развитую инфраструктуру, доставшуюся от СССР, выгодное экономико-географическое положение, позволяющее выступать в качестве связующего звена между несколькими регионами мира. Во втором большое значение, прежде всего, имел богатый ресурсный потенциал, ставивший Азербайджан в число наиболее перспективных экспортеров нефти и газа. Кроме того, обе страны рассматривали себя в качестве альтернативных «центров силы» постсоветского пространства, что также способствовало их сближению. Однако стоит отметить, что не во всех ключевых вопросах Украина и Азербайджан придерживались схожих позиций.

Сфера ВТС была и остается наиболее успешной для сотрудничества Украины и Азербайджана. Промышленные мощности, технологическая база и большие запасы вооружений, доставшиеся от СССР, позволили Киеву выступать в качестве надежного поставщика и партнера. Азербайджан, потерпевший военное поражение в ходе НагорноКарабахского конфликта, нуждался в восстановлении потенциала вооруженных сил, перевооружении и модернизации армии. Вплоть до 2014 г., Киев неизменно входил в число ведущих поставщиков вооружений и технологий, наряду с такими странами, как Турция, Россия и Израиль. Успехи в сфере ВТС позволяли Украине рассчитывать как на дальнейшее плодотворное сотрудничество в данной области (например, разработка совместных технологий и проектов), так и на лоббирование с помощью Азербайджана своих интересов в отношениях с Турцией или продвижение интересов в Каспийском регионе.

Сфера энергетики и поставок энергоресурсов с момента обретения независимости являлась одной из наиболее важных для Украины. Зависимость от российских углеводородов существенно ограничивала внешнеполитическую активность Киева, поэтому поиск альтернативных поставщиков и диверсификация маршрутов поставок были стратегической целью. Азербайджан, в свою очередь, нуждался в надежных транзитерах, способных предложить действующие трубопроводы или совместные проекты по их строительству. Украина, при всей выгодности своего геостратегического положения, не рассматривалась Баку в качестве приоритетного партнера, более выгодными и безопасными считались маршруты через Закавказье и Турцию. Киев же серьезно подпортил свой имидж в ходе «газовых войн» с Россией во второй половине 2000-х гг., когда главными пострадавшими стали европейские страны, оставшиеся без поставок российских энергоресурсов. Однако Азербайджан периодически реализовывал совместные проекты с Украиной (например, эксплуатация нефтепровода Одесса Броды), которые, впрочем, носили второстепенный характер. Фактически Азербайджан сотрудничал с Украиной в сфере энергетики по остаточному принципу, предпочитая реализовывать стратегические проекты с другими странами, но удерживая Киев менее значительными сделками и обещаниями расширения сотрудничества в будущем.

Позиции двух стран относительно конфликтов имеют большое количество схожих черт: стороны выступают в поддержку территориальной целостности друг друга, подвергают критике действия непризнанных государств, предлагают собственные варианты по урегулированию. Однако если позиция Украины по Нагорно-Карабахскому конфликту, сформулированная во второй половине 1990-х гг., во многом определялась экономическими причинами, то позиция Азербайджана относительно событий украинского кризиса и конфликта в Донбассе определялась как необходимостью сохранить Киев в качестве партнера, так и избежать серьезного ухудшения в отношениях с Россией. Кроме того, Азербайджан сумел использовать украинский кризис для привлечения международного внимания к Нагорному Карабаху, поскольку эта тема долгое время оставалась на информационной «периферии».

Наконец, Украина и Азербайджан, находясь в составе ГУАМ и «Восточного партнерства», по-разному рассматривали свои цели в рамках данных образований. ГУАМ играл роль потенциальной площадки для диверсификации маршрутов поставок азербайджанских энергоресурсов и, в более отдаленной перспективе, мог стать альтернативой для традиционных посредников в урегулировании «замороженных» конфликтов на постсовет- 
ском пространстве. Однако политические амбиции Украины и Грузии, неподкрепленные значительными экономическими возможностями и ресурсами, зависимость от влияния внешних факторов, акцентирование внимания на противодействии интересам России отрицательно сказались на эффективности действий организации.

«Восточное партнерство» изначально не рассматривалось в Азербайджане в качестве приоритетного проекта, поскольку европейская интеграция не являлась стратегической целью его внешней политики. Инициативы, проекты и финансовые вливания позволили Баку провести ряд успешных экономических реформ, но практически никак не отразились на внутриполитической сфере. Украина, в свою очередь, рассчитывала с помощью «Восточного партнерства» упрочить свои позиции в Европе.

В целом, можно констатировать, что украинско-азербайджанские отношения представляют собой весьма интересный пример для постсоветского пространства, поскольку отличаются высоким уровнем стабильности, отсутствием существенных противоречий, наличием общих интересов и схожих проблем. Также в отношениях между Киевом и Баку фактически отсутствует элементы принуждения или односторонней зависимости, что позволяет развивать именно равноправное партнерство. Действительно, Азербайджан имеет существенный «козырь» в виде энергоресурсов, но Украина частично компенсирует его за счет ВТС. Тем не менее более заинтересованной стороной можно считать Украину, поскольку именно Киев в официальных документах рассматривает Азербайджан в качестве стратегического партнера.

Говоря о перспективах украинско-азербайджанских отношений, стоит понимать, что стороны в данный момент переживают совершенно противоположные этапы в своем развитии. Если Азербайджан укрепляет свои позиции в Каспийском регионе и, в перспективе, способен стать одним из важных поставщиков углеводородов на европейский рынок, то Украина переживает кризисные явления, которые влияют не только на статус страны в системе международных отношений, но и бросают вызов самой украинской государственности. Существующие четыре ключевых сферы сотрудничества уже сейчас нуждаются в пересмотре, поскольку некоторые уже морально устарели (сотрудничество в рамках ГУАМ и «Восточного партнерства»), другие могут быть пересмотрены в пользу иных партнеров (Азербайджан активно развивает ВТС с несколькими государствами). В случае сосредоточения Украины на решении внутренних проблем или окончательной переориентации внешней политики на «европейский выбор», отношения двух стран сохранят характер стратегических только в официальных документах. Однако экономическое сотрудничество и позиции в отношении Нагорного Карабаха и Донбасса, как минимум в среднесрочной перспективе, не будут иметь оснований для пересмотра или внесения кардинальных изменений.

\section{Список литературы}

1. Алексеева Н.А. «Инородное тело»: сможет ли Украина вступить в торгово-политический союз с Турцией и Азербайджаном // RT на русском. Официальный сайт. URL: https://russian.rt.com/world/article/489347-turciya-azerbaydzhan-ukraina-soyuz (дата обращения: 17.10.2019).

2. Андронова И.В. 2010. Внешнеэкономические аспекты национальных интересов России на постсоветском пространстве. М.: Квадрига, 383.

3. Бабенко В.Н. 2016. «Майданная» Украина (2005-2014): между Россией и Евросоюзом // Россия и современный мир. № 3: 115-128.

4. Белащенко Д.А. 2012. Особенности внешней политики Украины на Кавказе // Вестник Нижегородского университета им. Н.И. Лобачевского. № 3. 337-342.

5. Быков А.Н. 2009. Постсоветское пространство. Стратегии глобализации и новые вызовы интеграции. СПб.: Алетейя, 192.

6. В ожидании бури: Южный Кавказ / М.С. Барабанов, М. Йешильташ, А.В. Лавров, Н.А. Ломов, Ю.Ю. Лямин, Л.А. Нерсисян, А.В. Никольский, М. Серен, И.А. Топчий; под ред. К.В. Макиенко. М.: Центр анализа стратегий и технологий, 2018, 200.

7. Внешняя политика стран СНГ: Учеб. пособие для студентов вузов / Ред.-сост. Д.А. Дегтерев, К.П. Курылев. М.: Издательство «Аспект Пресс», 2017, 496.

8. Гомулка К. 2015. Реализация инициатив «Восточного партнерства» в Азербайджане // Историческая и социально-образовательная мысль. № 7-1: 46-55. 
9. Губа К.В. 2012. Киев-Баку: три «кита» двусторонних отношений // Одна Родина. Официальный сайт. URL: https://odnarodyna.org/content/kiev-baku-tri-kita-dvustoronnih-otnosheniy (дата обращения: 17.10.2019).

10. Гулиев А.Д. 2014. Украино-азербайджанские отношения: право, политика, дипломатия: сб. научных трудов. Том 1. Харьков: Факт, 656.

11. Гулиев А.Д. 2015. Украино-азербайджанские отношения: право, политика, дипломатия: сб. научных трудов. Том 2. Харьков: Факт, 572.

12. Гулиев А.Д. 2017. Украино-азербайджанские отношения: право, политика, дипломатия: сб. научных трудов. Том 3. Харьков: Факт, 564.

13. Курылев К.П. 2019. Факторы, определявшие внешнюю политику Украины по вопросу Нагорно-Карабахского урегулирования (1992-1994 гг.) // 30-летие конфликта в Нагорном Карабахе: сборник научных статей / под ред. К.П. Курылева. М.: РУДН: 40-51.

14. Маркедонов С.М. 2018. Тридцать лет Нагорно-Карабахского конфликта: основные этапы и перспективы урегулирования // Постсоветские исследования. Т. 1. № 2: 129-138.

15. Ниязов Н.С. 2014. Военно-техническое сотрудничество Украины и Азербайджана в 1994-2014 годах // Кавказ и глобализация. Т. 8. № 3-4: 35-46.

16. Пивовар Е.И. 2008. Постсоветское пространство: альтернативы интеграции. Исторический очерк. СПб.: Алетейя, 320.

17. Полухов Э.П. ГУАМ: Взгляд из Азербайджана // Центральная Азия и Кавказ (специальный выпуск). № 3-4(57-58): 134-144.

18. Порошенко позвал Алиева на войну // RealNewsLand.ru. 2018. URL: https://realnewsland.ru/ukraine/118035-poroshenko-pozval-alieva-na-vojnu.html (дата обращения: 17.01.2020).

19. Роль, место и вес азербайджанской диаспоры в Украине: что объединяет наши народы интервью // Новая Эпоха. 2019. URL: https://yenicag.ru/rol-mesto-i-ves-azerbaydzhanskoy$\operatorname{dias} / 293866 /$ (дата обращения: 17.01.2020).

20. Татаринцев В.М. 2011. Двусторонние отношения России со странами СНГ: Монография. М.: Восток - Запад, 2011, 264.

21. Aliev N. 2007. Armenian-Azerbaijani Nagorno-Karabakh Conflict in the Context of International Law // The Caucasus and Globalization. Vol. 1(2): 17-24.

22. Croissant M.P., Aras B. 1999. Oil and Geopolitics in the Caspian Sea Region. Greenwood Publishing Group, 305.

23. Kembayev Z. 2009. Legal Aspects of the Regional Integration Processes in the Post-Soviet Area. Springer-Verlag Berlin Heidelberg, 222.

24. Özdal H., Demydova V. 2011. Turkey-Ukraine Relations: High Potential, Low Voltage. International Strategic Research Organization (USAK), 50.

25. The International Politics of the Armenian-Azerbaijani Conflict: The Original «Frozen Conflict» and European Security. Editor S.E. Cornell. Palgrave Macmillan US, 2017, 227.

26. Valiyev A. 2014 Azerbaijan's Balancing Act in the Ukraine Crisis. PONARS Eurasia Policy Memo №. 352, 5.

27. Valiyev A. 2017. Azerbaijan's Foreign Policy: What Role for the West in the South Caucasus? // Eastern Voices: Europes's East Faces an Unsettled West: 135-149.

\section{References}

1. Alekseeva N.A. «Inorodnoe telo»: smozhet li Ukraina vstupit' v torgovo-politicheskiy soyuz s Turtsiey i Azerbaydzhanom // RT na russkom. Ofitsial'nyy sayt. URL: https://russian.rt.com/world/article/489347-turciya-azerbaydzhan-ukraina-soyuz (дата обращения: 17.10.2019).

2. Andronova I.V. 2010. Vneshneekonomicheskie aspekty natsional'nykh interesov Rossii na postsovetskom prostranstve. M.: Kvadriga, 383.

3. Babenko V.N. 2016. «Maydannaya» Ukraina (2005-2014): mezhdu Rossiey i Evrosoyuzom // Rossiya i sovremennyy mir. № 3: 115-128.

4. Belashchenko D.A. 2012. Osobennosti vneshney politiki Ukrainy na Kavkaze // Vestnik Nizhegorodskogo universiteta im. N.I. Lobachevskogo. № 3. 337-342 (in Russian).

5. Bykov A.N. 2009. Postsovetskoe prostranstvo. Strategii globalizatsii i novye vyzovy integratsii. SPb.: Aleteyya, 192.

6. V ozhidanii buri: Yuzhnyy Kavkaz / M.S. Barabanov, M. Yeshil'tash, A.V. Lavrov, N.A. Lomov, Yu.Yu. Lyamin, L.A. Nersisyan, A.V. Nikol'skiy, M. Seren, I.A. Topchiy; pod red. K.V. Makienko. M.: Tsentr analiza strategiy i tekhnologiy, 2018, 200. 
7. Vneshnyaya politika stran SNG: Ucheb. posobie dlya studentov vuzov / Red.-sost. D.A. Degterev, K.P. Kurylev. M.: Izdatel'stvo «Aspekt Press», 2017, 496.

8. Gomulka K. 2015. Realizatsiya initsiativ «Vostochnogo partnerstva» v Azerbaydzhane // Istoricheskaya i sotsial'no-obrazovatel'naya mysl'. № 7-1: 46-55.

9. Guba K.V. 2012. Kiev-Baku: tri «kita» dvustoronnikh otnosheniy // Odna Rodina. Ofitsial'nyy sayt. URL: https://odnarodyna.org/content/kiev-baku-tri-kita-dvustoronnih-otnosheniy (дата обращения: 17.10.2019).

10. Guliev A.D. 2014. Ukraino-azerbaydzhanskie otnosheniya: pravo, politika, diplomatiya: sb. nauchnykh trudov. Tom 1. Khar'kov: Fakt, 656.

11. Guliev A.D. 2015. Ukraino-azerbaydzhanskie otnosheniya: pravo, politika, diplomatiya: sb. nauchnykh trudov. Tom 2. Khar'kov: Fakt, 572.

12. Guliev A.D. 2017. Ukraino-azerbaydzhanskie otnosheniya: pravo, politika, diplomatiya: sb. nauchnykh trudov. Tom 3. Khar'kov: Fakt, 564.

13. Kurylev K.P. 2019. Faktory, opredelyavshie vneshnyuyu politiku Ukrainy po voprosu Nagorno-Karabakhskogo uregulirovaniya (1992-1994 gg.) // 30-letie konflikta v Nagornom Karabakhe: sbornik nauchnykh statey / pod red. K.P. Kuryleva. M.: RUDN: 40-51.

14. Markedonov S.M. 2018. Tridtsat' let Nagorno-Karabakhskogo konflikta: osnovnye etapy i perspektivy uregulirovaniya // Postsovetskie issledovaniya. T. 1. № 2: 129-138.

15. Niyazov N.S. 2014. Voenno-tekhnicheskoe sotrudnichestvo Ukrainy i Azerbaydzhana v 1994-2014 godakh // Kavkaz i globalizatsiya. T. 8. № 3-4: 35-46.

16. Pivovar E.I. 2008. Postsovetskoe prostranstvo: al'ternativy integratsii. Istoricheskiy ocherk. $\mathrm{SPb} .:$ Aleteyya, 320.

17. Polukhov E.P. GUAM: Vzglyad iz Azerbaydzhana // Tsentral'naya Aziya i Kavkaz (spetsial'nyy vypusk). № 3-4(57-58): 134-144.

18. Poroshenko pozval Alieva na vojnu. 2018. RealNewsLand.ru. URL: https://realnewsland.ru/ukraine/118035-poroshenko-pozval-alieva-na-vojnu.html (data obrashcheniya: 17.01.2020).

19. Rol', mesto i ves azerbajdzhanskoj diaspory v Ukraine: chto ob"edinyaet nashi narody - interv'yu. 2019. Novaya Epoha. URL: https://yenicag.ru/rol-mesto-i-ves-azerbaydzhanskoy-dias/293866/ (data obrashcheniya: 17.01.2020).

20. Tatarintsev V.M. 2011. Dvustoronnie otnosheniya Rossii so stranami SNG: Monografiya. M.: Vostok - Zapad, 2011, 264.

21. Aliev N. 2007. Armenian-Azerbaijani Nagorno-Karabakh Conflict in the Context of International Law // The Caucasus and Globalization. Vol. 1(2): 17-24.

22. Croissant M.P., Aras B. 1999. Oil and Geopolitics in the Caspian Sea Region. Greenwood Publishing Group, 305.

23. Kembayev Z. 2009. Legal Aspects of the Regional Integration Processes in the Post-Soviet Area. Springer-Verlag Berlin Heidelberg, 222.

24. Özdal H., Demydova V. 2011. Turkey-Ukraine Relations: High Potential, Low Voltage. International Strategic Research Organization (USAK), 50.

25. The International Politics of the Armenian-Azerbaijani Conflict: The Original «Frozen Conflict» and European Security. Editor S.E. Cornell. Palgrave Macmillan US, 2017, 227.

26. Valiyev A. 2014 Azerbaijan's Balancing Act in the Ukraine Crisis. PONARS Eurasia Policy Memo №. 352, 5.

27. Valiyev A. 2017. Azerbaijan's Foreign Policy: What Role for the West in the South Caucasus? // Eastern Voices: Europes's East Faces an Unsettled West: 135-149.

\section{Ссылка для цитирования статьи Reference to article}

Белащенко Д.А., Шоджонов И.Ф. 2020. Украинско-азербайджанские отношения: основные сферы сотрудничества, проблемы и перспективы развития. Via in tempore. История. Политология, 47(1): 202-210. DOI 10.18413/2687-0967-2020-47-1-202-210

Belashchenko D.A., Shodzhonov I.F. 2020. Ukraine-azerbaijan relations: basic fields of cooperation, problems and prospects for development. Via in tempore. History and political science, 47(1): 202-210 (in Russian). DOI 10.18413/2687-0967-2020-47-1-202-210 